\title{
CAEP 2016 Academic Symposium: A Writer's Guide to Key Steps in Producing Quality Medical Education Scholarship
}

Teresa M. Chan, BEd, HBSc, MD, MHPE*; Brent Thoma, MA, MD, MSc ${ }^{\dagger}$; Andrew Koch Hall, MD, $\mathrm{MMEd}^{\ddagger}$; Aleisha Murnaghan, BSc, MD, MHPE ${ }^{\S}$; Daniel K. Ting, MD"; Carly Hagel, BSc, MD ${ }^{\ddagger}$; Kristen Weersink, MD, MSc ${ }^{\ddagger}$; Paola Camorlinga, BSc, MDף; Jill McEwen, MD"; Farhan Bhanji, MD, MSc**; Jonathan Sherbino, MD, MEd*

\section{ABSTRACT}

A key skill for successful clinician educators is the effective dissemination of scholarly innovations and research. Although there are many ways to disseminate scholarship, the most accepted and rewarded form of educational scholarship is publication in peer-reviewed journals.

This paper provides direction for emergency medicine (EM) educators interested in publishing their scholarship via traditional peer-reviewed avenues. It builds upon four literature reviews that aggregated recommendations for writing and publishing high-quality quantitative and qualitative research, innovations, and reviews. Based on the findings from these literature reviews, the recommendations were prioritized for importance and relevance to novice clinician educators by a broad community of medical educators.

The top items from the expert vetting process were presented to the 2016 Canadian Association of Emergency Physicians (CAEP) Academic Symposium Consensus Conference on Education Scholarship. This community of EM educators identified the highest yield recommendations for junior medical education scholars. This manuscript elaborates upon the top recommendations identified through this consensus-building process.

\section{RÉSUMÉ}

L'une des principales clés du succès parmi les médecins cliniciens enseignants est la diffusion efficace des travaux scientifiques touchant la recherche ou l'innovation. Certes, il existe de nombreux moyens de diffuser des travaux scientifiques, mais la forme la plus courante et la plus prestigieuse est la publication de travaux de recherche en éducation dans des revues à comité de lecture.

Les auteurs offrent, dans l'article, une voie à suivre aux médecins enseignants en médecine d'urgence (MU), désireux de publier leurs travaux scientifiques par la voie classique des articles évalués par les pairs. Le contenu repose sur quatre examens de la documentation qui ont permis de dégager des recommandations sur la rédaction et la publication de travaux de qualité concernant la recherche quantitative ou qualitative, les rapports sur l'innovation ou les revues systématiques. Les recommandations, tirées des examens de la documentation, ont été classées par ordre de priorité en fonction de l'importance et de la pertinence pour les nouveaux cliniciens enseignants, par un large éventail de médecins enseignants. Les principaux éléments extraits de cet examen détaillé, réalisé par des experts, ont été présentés durant la conférence consensuelle sur les travaux scientifiques en enseignement, tenue dans le cadre du Symposium sur les affaires universitaires de l'ACMU de 2016. La communauté de cliniciens enseignants en MU a dégagé les recommandations qui leur semblaient les plus utiles aux jeunes chercheurs en enseignement de la médecine. L'article fait donc état des principales recommandations relevées tout le long de ce processus consensuel d'édification.

Keywords: academic writing, education scholarship, publishing

\section{INTRODUCTION}

Emergency medicine (EM) is committed to medical education. ${ }^{1}$ Previous work by the Academic Section of the Canadian Association of Emergency Physicians (CAEP) demonstrates that our discipline is involved in teaching at every Canadian medical school. ${ }^{2}$ However, the volume of our specialty's contribution to education scholarship is not proportional. Improved dissemination is vital to advance the field because it allows educators to build on each other's work. ${ }^{3}$

From the *Division of Emergency Medicine, Department of Medicine, Program for Education Research and Development, McMaster University, Hamilton, ON; †Department of Emergency Medicine, University of Saskatchewan, Saskatoon, SK; ¥Department of Emergency Medicine, Queen's University, Kingston, ON; §Department of Emergency Medicine, University of Ottawa, Ottawa, ON; IDepartment of Emergency Medicine, University of British Columbia, Vancouver, BC; and the ${ }^{* *}$ Centre for Medical Education, McGill University, Montreal, QC.

Correspondence to: Teresa M. Chan, 237 Barton St. E., McMaster Clinics, Room 255, Hamilton, ON L8L 2X2; Email: teresa.chan@medportal.ca 
In 2013, Bhanji et al. created a "how-to" guide for EM education scholarship. ${ }^{4}$ This primer served as a launching point to inspire clinical teachers interested in engaging in scholarship. The dissemination of EM-relevant education research and scholarship has many merits, ranging from personal satisfaction and academic recognition ${ }^{4}$ to improved learning environments and enhanced patient care. This dissemination may galvanize a national community of practice, allowing clinician educators to learn from each other's successes and failures.

Unfortunately, the quality of Canadian medical education scholarship has lagged behind that of our clinical research. ${ }^{3}$ Novice academics, in particular, have had difficulty publishing within medical education: rejection rates from medical education journals can be $87 \%$ or higher, and there are not as many venues or guides to publication available to medical education researchers. ${ }^{5}$ Fortunately, studies have shown that many flaws leading to manuscript rejection are preventable or fixable, ${ }^{6}$ suggesting that, through guidance and support, it may be possible to increase the dissemination of medical education research.

The purpose of this 2016 CAEP Academic Symposium consensus conference was to highlight key steps to elevate the level of Canadian EM education scholarship by providing high-yield recommendations to education scholars attempting to disseminate their research via peer-reviewed publication. Herein, we identify the key quality markers for quantitative research, qualitative research, innovation reports, reviews, and knowledge synthesis studies within medical education.

\section{METHODS}

In 2016, the Academic Section of CAEP held its second consensus conference on education. In preparation for this consensus conference, a series of four structured literature reviews were conducted to identify markers of high-quality education publications.

\section{Search methodology}

We conducted a series of scoping reviews to aggregate advice from the literature about how to best write four types of education scholarship manuscript: quantitative studies, ${ }^{7}$ qualitative studies, ${ }^{8}$ innovation reports, ${ }^{9}$ and reviews/synthesis works. ${ }^{10}$ These reviews resulted in distinct, genre-specific lists of quality markers related to these types of education scholarship. The number of items identified by each group ranged from 30 for innovation reports 9 to 157 for quantitative research. ${ }^{7}$ It was recognized that the high number of recommendations limited their practical application. A consensus process was used to identify key items.

\section{External validation of quality indicator lists}

To triangulate our findings and triage the essential markers of quality, an online survey for each category of scholarship was conducted. Four surveys (one for each topic) were published on CanadiEM.org weekly from April 4, 2016 to May 1, 2016 and emailed to the corresponding authors of key papers found in the literature reviews. We also attempted to crowd-source the expert opinions of relevant EM and medical education virtual communities of practice using social media. ${ }^{11,12}$ Specifically, the surveys were promoted on Twitter using the hashtags \#MedEd (Medical Education) and \#FOAMed (Free Open Access Medical education) and on the CanadiEM Facebook page. The survey also allowed participants to submit additional quality elements not identified by the thematic analysis using free text. Demographic information on survey participants was captured.

This survey allowed us to incorporate the expertise of medical educators unable to attend the consensus conference. Survey participants were asked to identify the top 25 quality markers by endorsing whether they thought each of the items should be included in the final list. Appendix A (see supplementary material) includes the surveys and demographics of survey respondents. Appendix B provides the top 25 quality markers for each category of medical education scholarship identified by the survey participants.

\section{Consensus conference final ranking}

Poster presentations containing the top 25 quality markers for the four categories of education scholarship were provided to the 2016 CAEP Academic Symposium on Education Scholarship Consensus Conference participants. In the event of a tie for the 25 th item, all items tied for that position were included. Each item was listed along with the percentage of votes that it received in the online consensus process.

Using a previously published methodology for achieving a group consensus, ${ }^{13-19}$ participants reviewed each of the four posters in a small group and indicated the top five most important elements in each by placing a sticker next to them. Participants were also asked to add 
any additional relevant items not represented within the list for each category. The key items for each category were presented to the reassembled large group of consensus conference participants for endorsement or amendment during the conference proceedings. This process was facilitated by the authors of this report.

\section{Recommendation review}

Following the consensus conference, selected recommendations for each of the four categories were reviewed. Although there were significant disparities between the consensus recommendations, four common themes were identified by the authors, which were represented in nearly every category. These recommendations were explicitly identified and expanded upon as the top four items of importance for the dissemination of all types of medical education research by the consensus conference.

\section{RECOMMENDATIONS}

Figure 1 outlines the four thematic elements identified by the consensus conference as being important to the success of those seeking to publish their education scholarship. Figure 2 outlines the top key categoryspecific recommendations in each area. Further clarification of these items can be found in Appendix C (see supplementary material).

\section{DISCUSSION}

In the Canadian EM education community, there is an increasing desire to encourage teachers and educators to generate scholarship., ${ }^{3,422}$ The Education Working Group within CAEP's Academic Section has sought to encourage the scholarly dissemination of work so that EM educators from across the country can improve their teaching techniques and educational systems. The first series of papers from the 2013 Academic Symposium 1) helped define education scholarship, ${ }^{22}$ 2) described how we could support careers of educators, ${ }^{23}$ and 3) provided beginners with a guide on how to begin developing a scholarly track record. ${ }^{4}$ We sought to build upon this previous work by assisting educators in generating high quality education scholarship.

Because many novice educators find the traditional peer review publication processes daunting, we sought to isolate the most common stumbling blocks and provide advice to overcome them. Our proceedings during this academic symposium allowed us to view the literature guiding education scholarship through the two lenses of most of the participants: the experienced educators who have mentored novice educators through the scholarly process, and the novice or junior educator who is entering into this field for the first time. By merging these two perspectives, we have generated four overall recommendations (see Figure 1) and multiple genre-specific recommendations (see Figure 2, with clarification in Appendix C).

\section{Recommendation 1: Respect related work and show that the research or innovation adds to the field}

It is critical for education scholars to conduct a thorough, up-to-date, and critical literature search to ground their work in the existing literature., ${ }^{4,24-26}$ Per Bordage, incorporating a "...thoughtful, focused, up-to-date review of the literature..." was one of the top five reasons for recommending acceptance of a manuscript. ${ }^{6}$ Failing to cite recent literature or citing only local examples can be a red flag for editors. ${ }^{27}$ Moreover, once links to previous work have been demonstrated, authors need to articulate how an innovation is novel or fills a void in the current literature. $^{28-30}$

\section{Recommendation 2: Use existing conceptual frameworks and theories to inform and guide scholarship}

Conceptual frameworks are ways of thinking about a study or a dilemma, a lens through which one can examine the complexities of educational or social phenomenon. ${ }^{31}$

\begin{tabular}{|l|l|}
\hline Recommendation 1: & Respect related work and show that the research or innovation adds to the field. \\
\hline Recommendation 2: & Use existing conceptual frameworks and theories to inform and guide scholarship. \\
\hline Recommendation 3: & $\begin{array}{l}\text { State clearly the goal(s) or question(s) of the article, ensuring that they are timely, relevant, prevalent, } \\
\text { and/or necessary. }\end{array}$ \\
\hline Recommendation 4: & Respect category-specific conventions when submitting for publication. \\
\hline
\end{tabular}

Figure 1. Key Elements of Publishable Medical Education Scholarship 


\begin{tabular}{|c|c|}
\hline $\begin{array}{c}\text { Key Recommendations for Clarification } \\
\text { about Quantitative Medical Education } \\
\text { Scholarship }\end{array}$ & $\begin{array}{l}\text { Key Recommendations for Clarification about } \\
\text { Qualitative Medical Education Scholarship }\end{array}$ \\
\hline $\begin{array}{l}\text { 1. Ensure the research question is } \\
\text { important to a key audience within the } \\
\text { field medical education. }{ }^{26,35-38} \\
\text { 2. Define a unique research question } \\
\text { before justifying the most appropriate } \\
\text { methodology to answer it. }{ }^{26,34,35,40-46} \\
\text { 3. Define clearly the population of interest } \\
\text { and the inclusion/exclusion criteria of } \\
\text { participants. }{ }^{39,47} \\
\text { 4. Discuss the results in relation to the } \\
\text { strengths and weaknesses in the } \\
\text { methodology. }\end{array}$ & $\begin{array}{l}\text { 1. Declare and report one's theoretical } \\
\text { paradigms, values, or position. }{ }^{23,48,49} \\
\text { 2. Use a sampling plan that ensures that } \\
\text { participants are relevant to the research } \\
\text { question; ensure participant selection is well- } \\
\text { reasoned. } \\
\text { 3. Ensure that the data collection is } \\
\text { comprehensive enough to support rich and } \\
\text { robust observations of the } \\
\text { observed/experienced events. } \\
\text { 4. Use techniques to minimize biased or } \\
\text { incomplete analysis: sufficiency }{ }^{52} \text {, } \\
\text { triangulation } \\
\text { (a.k.a. member checking), and fair dealing. }{ }^{52}{ }^{52} \\
\text { 5. Critique the study, reflecting on whether the } \\
\text { results are readily transferable. } .^{53}\end{array}$ \\
\hline $\begin{array}{l}\text { Key Recommendations for Clarification } \\
\text { about Reviews \& Synthesis Scholarship }\end{array}$ & $\begin{array}{l}\text { Key Recommendations for Clarification about } \\
\text { Innovation Scholarship }\end{array}$ \\
\hline $\begin{array}{l}\text { 1. Justify the type of review (e.g. } \\
\text { systematic review, meta-analysis, } \\
\text { scoping review, etc.). }{ }^{22,54} \\
\text { 2. Specify criteria for study eligibility giving } \\
\text { a rationale. }{ }^{3,54-59} \\
\text { 3. Describe how quality was assessed. }{ }^{22,57-60} \\
\text { 4. Summarize main findings, including } \\
\text { strength of evidence for each main } \\
\text { outcome. } .^{22,54,58} \\
\text { 5. Interpret the results in the context of } \\
\text { other evidence and provide implications } \\
\text { for future research. } .^{22,54,56,58,63}\end{array}$ & $\begin{array}{l}\text { 1. Present a clear and thorough description of } \\
\text { the problem, its importance and the need for } \\
\text { innovation, including how the problem has } \\
\text { been identified, and who is affected. }{ }^{26,64,65} \\
\text { 2. Present justification for the innovation } \\
\text { to pass the "who cares?" test. } \text {. }^{33,65} \\
\text { 3. Describe clearly the innovation-specific } \\
\text { metrics used to evaluate the innovation. } \\
\text { 4. Describe both successes and failure in } \\
\text { implementation, and subsequent lessons } \\
\text { learned. }{ }^{33,53,65} \\
\text { 5. State clearly the impact of the innovation on } \\
\text { the field. } .^{24,65,67}\end{array}$ \\
\hline
\end{tabular}

Figure 2. Key Genre-based Recommendations for Medical Education Scholarship

These frameworks can act to "illuminate and magnify" 32 various aspects of education scholarship. The lack of a conceptual or theoretical framework led to the rejection of manuscripts submitted to major educational journals $62.2 \%$ of the time. ${ }^{6}$ An exception to this rule may be in the development of a new theory via quantitative methods such as grounded theory. Even then, however, it is important to ensure that links to previous similar work are made. ${ }^{33}$

\section{Recommendation 3: State clearly the goal(s) or question(s) of the manuscript, ensuring that they are timely, relevant, prevalent, and/or necessary}

Having an important goal is key to successful publication ${ }^{34}$ and a top reason that reviewers used to explain why they recommended acceptance of papers. ${ }^{6}$ The academic community values clarity of writing. ${ }^{20,21}$ Editors, ${ }^{27}$ reviewers, ${ }^{27}$ and especially readers ${ }^{30}$ benefit from clear articulation of the intentions underpinning scholarship. ${ }^{35}$

\section{Recommendation 4: Respect category-specific conventions when submitting for publication}

The various categories of medical education scholarship have different conventions. When writing a paper, it is important that authors adhere to the language and style specific to each of these categories. Figure 2 more fully identifies key recommendations that must be considered for different categories of education scholarship, and these recommendations are more fully clarified within Appendix C.

With regards to all types of scholarship, it is crucial to explain why a particular study is important, and more specifically, to whom it is important. Many reviewers and editors will remind authors to answer two central questions: "So what?" and "Who cares?" The "So what?" question ensures that you have clearly made a case for why your research question is novel and interesting to the field. At times, a study may answer a 
new question or add a new innovative spin to previous work. Other times, a study may replicate or contradict previous findings or theories.

Junior authors should seek the mentorship of those more well-versed in an area for help when writing their manuscripts. An experienced educator may know of work that is linked conceptually but may not have been studied in the exact same context (e.g., work in intensive care unit education may be relevant to an author who is seeking to study emergency consultations skills). Linking to previous literature is of the utmost importance when reporting new findings. $4,6,24-26$

Completing a thorough review of the literature is advisable, but this preparatory reading will not always lead to a publishable manuscript. ${ }^{10}$ Reviews of previous literature may not coalesce into meta-analyses or systematic reviews because the existing literature is too heterogeneous to answer a defined question. ${ }^{10}$ Clearly defined questions for synthesis works are important, but the aggregation of data must first be justifiable, as we point out in our genre-specific recommendations (see Figure 2).

Finally, we would like to advise educators that works on scholarly innovation are important; however, not every educational endeavour will be innovative. Innovation reporting requires the same amount of rigour as other forms of scholarship, with the same necessity to build upon previous work and add new ideas. ${ }^{9}$ Careful thought should be placed into whether the work of scholarship is best disseminated as an innovation report, or whether it is best delivered to other educators as a package of peer-reviewed teaching materials via new scholarly portals ${ }^{3,4}$ (such as MedEdPortal, JETem.org, EMSimCases.com, etc.).

\section{LIMITATIONS}

The main limitation of our study was that the demographic make-up of consensus conference participants was not optimal or selective. An open call for participation was made to all emergency physician members of CAEP, potentially limiting a broader inclusion of EM educators. Also, the demographics of participants indicated significant representation from very early career EM scholars (students, residents, and junior educators) who may lack significant experience in medical education scholarship. Thus, the endorsement of key steps may be influenced by limited or inexperienced consensus.

\section{CONCLUSION}

Education scholarship is imperative to advance EM education. To effectively publish and disseminate education scholarship, it is important to prevent fatal flaws. ${ }^{4,6,24-26,36,37}$ Clinician educators are a prime source of innovations and research that can advance the field of medical education, and we hope that this document and its associated reviews ${ }^{7-10}$ will help foster continued education scholarship amongst the ranks of EM educators. This guide serves as a primer for both novice education scholars and clinician educators to assist in elevating EM education scholarship by attending to key steps in the publication process.

Competing interests: None declared.

\section{SUPPLEMENTARY MATERIAL}

To view supplementary material for this article, please visit https://doi.org/10.1017/cem.2017.30

\section{REFERENCES}

1. Gordon JA. Reflections on the consensus process: a leadership role for emergency medicine in educational scholarship and practice across health care. Acad Emerg Med 2012; 19(12):1333-5, doi:10.1111/acem.12020.

2. Stiell IG, Artz JD, Lang ES, et al. An environmental scan of academic emergency medicine at the 17 Canadian medical schools: why does this matter to emergency physicians? CFEM 2017;19(1):39-46, doi:10.1017/cem.2016.346.

3. Sherbino J. Education scholarship: the next step for our specialty. CFEM 2010;12(4):347-8.

4. Bhanji F, Cheng A, Frank JR, et al. Education scholarship in emergency medicine part 3: a "how-to" guide. CFEM 2014; 16(Suppl 1):S13-8, doi:10.2310/8000.2014.141456.

5. Norman G. Data dredging, salami-slicing, and other successful strategies to ensure rejection: twelve tips on how to not get your paper published. Adv Heal Sci Educ 2014;19(1):1-5, doi:10.1007/s10459-014-9494-8.

6. Bordage G. Reasons reviewers reject and accept manuscripts: the strengths and weaknesses in medical education reports. Acad Med 2001;76(9):889-96, doi:10.1097/ 00001888-200109000-00010.

7. Thoma B, Camorlinga P, Chan TM, et al. A writer's guide to education scholarship: quantitative methodologies for medical education research (part 1). CFEM 2017; doi:10.1017/cem.2017.17. In press.

8. Chan TM, Ting DK, Hall AK, et al. A writer's guide to education scholarship: qualitative education scholarship (part 2). CFEM 2017; doi:10.1017/cem.2017.17. In press.

9. Hall AK, Hagel C, Chan TM, et al. A writer's guide to education scholarship in emergency medicine: education innovations (part 3). CFEM 2017; doi:10.1017/cem.2017.28. In press. 
10. Murnaghan A, Weersink K, Thoma B, et al. A writer's guide to education scholarship in emergency medicine: systematic reviews and the scholarship of integration (part 4). CFEM 2017; doi:10.1017/cem.2017.29. In press.

11. Zhao Y, Zhu Q. Evaluation on crowdsourcing research: current status and future direction. Inf Syst Front 2014; 16(3):417-34, doi:10.1007/s10796-012-9350-4.

12. Thoma B, Paddock M, Purdy E, et al. Leveraging a virtual community of practice to participate in a survey-based study: a description of the METRIQ study methodology. AEM Educ Train 2016; doi:10.1002/aet2.10013.

13. Rodriguez E, Siegelman J, Leone K, et al. Assessing professionalism: summary of the working group on assessment of observable learner performance. Acad Emerg Med 2012;19(12):1372-8, doi:10.1111/acem.12031.

14. Salzman DH, Franzen DS, Leone KA, et al. Assessing practice-based learning and improvement. Acad Emerg Med 2012;19(12):1403-10, doi:10.1111/acem.12026.

15. Goyal N, Aldeen A, Leone K, et al. Assessing medical knowledge of emergency medicine residents. Acad Emerg Med 2012;19(12):1360-5, doi:10.1111/acem.12033.

16. Chen EH, O'Sullivan PS, Pfennig CL, et al. Assessing systems-based practice. Acad Emerg Med 2012;19(12): 1366-71, doi:10.1111/acem.12024.

17. Takayesu JK, Kulstad C, Wallenstein J, et al. Assessing patient care: summary of the breakout group on assessment of observable learner performance. Acad Emerg Med 2012; 19(12):1379-89, doi:10.1111/acem.12038.

18. Kessler CS, Leone KA. The current state of core competency assessment in emergency medicine and a future research agenda: recommendations of the working group on assessment of observable learner performance. Acad Emerg Med 2012; 19(12):1354-9, doi:10.1111/acem.12023.

19. Chan TM, Wallner C, Swoboda TK, et al. Assessing interpersonal and communication skills in emergency medicine. Acad Emerg Med 2012;19(12):1390-402, doi:10.1111/acem.12030.

20. Cooper S, Endacott R. Generic qualitative research: a design for qualitative research in emergency care? Emerg Med 7 2007;24(12):816-9, doi:10.1136/emj.2007.050641.

21. Stacy R, Spencer J. Assessing the evidence in qualitative medical education research. Med Educ 2000;34(7):498-500.

22. Sherbino J, van Melle E, Bandiera G, et al. Education scholarship in emergency medicine part 1: innovating and improving teaching and learning. CFEM 2014;15(Suppl 1): S1-5, doi:10.2310/8000.2014.141454.

23. Bandiera G, Leblanc C, Regehr G, et al. Education scholarship in emergency medicine part 2: supporting and developing scholars. CFEM 2014;16(Suppl 1):S6-12, doi: $10.2310 / 8000.2014 .141455$.

24. McGee JB, Kanter SL. How we develop and sustain innovation in medical education technology: keys to success. Med Teach 2011;33:279-85, doi:10.3109/0142159X.2011. 540264.

25. Gordon M, Gibbs T. STORIES statement: publication standards for healthcare education evidence synthesis. $B M C$ Med 2014;12(1):143, doi:10.1186/s12916-014-0143-0.

26. Kitto S. Quality in qualitative research. Med 7 Aust 2008; 188(4):243-6, doi:10.4135/9781848608191.
27. Monrouxe L, Haidet P, Ginsburg S, et al. Good advice from the deputy editors of Medical Education. Med Educ 2012; 46(9):828-9, doi:10.1111/j.1365-2923.2012.04318.x.

28. Brien BCO, Harris IB, Beckman TJ, et al. Standards for reporting qualitative research. Acad Med 2014; 89(9):1245-51, doi:10.1097/ACM.0000000000000388.

29. Cook DA, Bowen JL, Gerrity MS, et al. Proposed standards for medical education submissions to the Fournal of General Internal Medicine. 7 Gen Intern Med2008;23(7):908-13, doi:10.1007/s11606-008-0676-z.

30. Sullivan GM, Simpson D, Cook DA, et al. Redefining quality in medical education research: a consumer's view. $\mathcal{F}$ Grad Med Educ 2014;6(3):424-9, doi:10.4300/JGME-D-1400339.1.

31. Bordage G. Conceptual frameworks to illuminate and magnify. Med Educ 2009;43(4):312-9, doi:10.1111/j.13652923.2009.03295.x.

32. Schwartz A, Pappas C, Bashook PG, et al. Conceptual frameworks in the study of duty hours changes in graduate medical education: a review. Acad Med 2011;86(1):18-29, doi:10.1097/ACM.0b013e3181ff81dd.

33. Charmaz K. Constructing grounded theory: a practical guide through qualitative analysis. Thousand Oaks, London, and New Delhi: Sage; 2006.

34. Yarris LM, Deiorio NM. Education research: a primer for educators in emergency medicine. Acad Emerg Med 2011; 18:S27-35, doi:10.1111/j.1553-2712.2011.01189.x.

35. Yarris LM, Juve AM, Coates WC, et al. Critical appraisal of emergency medicine education research: the best publications of 2014. Acad Emerg Med 2015;22(11):1327-36, doi:10.1111/acem.12801.

36. McGaghie WC. Scholarship, publication, and career advancement in health professions education: AMEE guide no. 43. Med Teach 2009;31(7):574-90, doi:10.1080/ 01421590903050366 .

37. Cook DA. Getting started in medical education scholarship. Keio 7 Med 2010;59(3):96-103.

38. Yarris LM, Gruppen LD, Hamstra SJ, et al. Overcoming barriers to addressing education problems with research design: a panel discussion. Acad Emerg Med 2012; 19(12):1344-9, doi:10.1111/acem.12025.

39. Norman G, Eva KW. Quantitative research methods in medical education. Underst Med Educ 2010;21:301-22, doi:10.1002/9781444320282.ch21.

40. Yarris LM, Deiorio NM. Education research: a primer for educators in emergency medicine. Acad Emerg Med 2011; 18(Suppl 2):S27-35.

41. Cook DA, Levinson AJ, Garside S. Method and reporting quality in health professions education research: a systematic review. Med Educ 2011;45(3):227-38.

42. Horn C, Plazas SB, Coverdale JH, et al. Educational research questions and study design 65. AcadPsychiatry 2009;33(1545-7230 [Electronic]):261-7.

43. Azer SA. Research in medical education is not just on telling a story. Saudi Med 7 2010;31(4):456-8.

44. Boet S, Sharma S, Goldman J, et al. Review article: medical education research: an overview of methods. Can $\mathcal{F}$ Anaesth 2012;59(2):159-70. 
45. Stone N. Evaluating interprofessional education: the tautological need for interdisciplinary approaches. 7 Interprof Care 2006;20(3):260-75.

46. Cook DA. Randomized controlled trials and meta-analysis in medical education: what role do they play? Med Teach 2012;34(6):468-73.

47. Ringsted C, Hodges B, Scherpbier A. "The research compass": an introduction to research in medical education: AMEE guide no. 56. Med Teach 2011;33(9):695-709, doi:10.3109/0142159X.2011.595436.

48. Cook DA, Levinson AJ, Garside S. Method and reporting quality in health professions education research: a systematic review. Med Educ 2011;45(3):227-38, doi:10.1111/j.1365-2923.2010.03890.x.

49. Coverdale JH, Roberts LW, Balon R, et al. Writing for academia: getting your research into print: AMEE guide no. 74. Med Teach 2013;35(2):e926-34.

50. Walsh K. Research into cost and value in medical education: can we make findings more generalisable? Commentary. Ann Ist Super Sanita 2014;50(1):4-5.

51. Hanson JL, Balmer DF, Giardino AP. Qualitative research methods for medical educators. Acad Pediatr 2006;11(5):375-86, doi:10.1016/j.acap.2011.05.001.

52. Boet S, Sharma S, Goldman J, et al. Medical education research: an overview of methods. Can 7 Anesth 2012;59:159-70, doi:10.1007/s12630-011-9635-y.

53. Kuper A, Reeves S, Levinson $W$. An introduction to reading and appraising qualitative research. BM7 2008;337:a288, doi:10.1136/bmj.a288.

54. Glassick CE. Boyer's expanded definitions of scholarship, the standards of assessing scholarship, and the elusiveness of the scholarship of teaching. Acad Med 2000;75(9): 877-80.

55. Sharma R, Gordon M, Dharamsi S, et al. Systematic reviews in medical education: a practical approach: AMEE guide 94. Med Teach 2015;37(2):108-24, doi:10.3109/0142159X.2014. 970996.

56. Conn VS, Isaramalai $\mathrm{S}$, Rath $\mathrm{S}$, et al. Beyond MEDLINE for literature searches. 7 Nurs Scholarsh 2003;35(2):177-82, doi:10.1111/j.1547-5069.2003.00177.x.
57. Cook DA, West CP. Conducting systematic reviews in medical education: a stepwise approach. Med Educ 2012; 46(10):943-52, doi:10.1111/j.1365-2923.2012.04328.x.

58. Kelly KD, Travers A, Dorgan $M$, et al. Evaluating the quality of systematic reviews in the emergency medicine literature. Ann Emerg Med 2001;38(5):518-26, doi:10.1067/ mem.2001.115881.

59. Moher D, Liberati A, Tetzlaff J, et al. Preferred reporting items for systematic reviews and meta-analyses: the PRISMA statement (reprinted from Annals of Internal Medicine). Phys Ther 2009;89(9):873-80, doi:10.1371/journal. pmed.1000097.

60. Reeves S, Koppel I, Barr H, et al. Twelve tips for undertaking a systematic review. Med Teach 2002;24(4):358-63, doi:10.1080/01421590220145707.

61. Hammick $M$, Dornan $T$, Steinert $Y$. BEME guide: conducting a best evidence systematic review. Part 1: from idea to data coding. BEME guide no. 13. Med Teach 2010; 32(1):3-15, doi:10.3109/01421590903414245.

62. Colquhoun HL, Levac D, O'Brien KK, et al. Scoping reviews: time for clarity in definition, methods, and reporting. 7 Clin Epidemiol 2014;67(12):1291-4, doi:10.1016/ j.jclinepi.2014.03.013.

63. Wong G, Greenhalgh T, Westhorp G, et al. Development of methodological guidance, publication standards and training materials for realist and meta-narrative reviews: the RAMESES (Realist And Meta-narrative Evidence Syntheses - Evolving Standards) project. Heal Serv Deliv Res 2014;2(30):1-252, doi:10.3310/hsdr02300.

64. Masic I. How to search, write, prepare and publish the scientific papers in the biomedical journals. Acta Inform Medica 2011;19(2):68-79.

65. Blanchard RD, Nagler A, Artino AR. Harvest the low-hanging fruit: strategies for submitting educational innovations for publication. 7 Grad Med Educ 2015;7(3): 318-22, doi:10.4300/JGME-D-15-00228.1.

66. Kanter SL. Toward better descriptions of innovations. Acad Med 2008;83(8):703-4, doi:10.1097/ACM.0b013e3181838a2c.

67. Barrows HS. Innovations without appropriate assessment are of limited usefulness. Teach Learn Med 2008;20(4):287, doi:10.1080/10401330802382148. 